\title{
Outcomes Following Primary Realignment Versus Suprapubic Cystostomy with Delayed Urethroplasty for Pelvic Fracture-Associated Posterior Urethral Injury: A Systematic Review with Meta-Analysis
}

\author{
Alexander Light Tanya Gupta Maria Dadabhoy Allen Daniel \\ Madura Nandakumar Abigail Burrows Sandeep Karthikeyan \\ GKT School of Medical Education, King's College London, Guy's Campus, London, UK
}

\section{Key Words}

Urethra $\cdot$ Urethral trauma $\cdot$ Primary realignment $•$

Endoscopic realignment $•$ Urethroplasty

\begin{abstract}
Objective: Pelvic fracture can be complicated by posterior urethral injury (PUI) in up to $25 \%$ of cases. PUI can produce considerable morbidity, including urethral stricture, erectile dysfunction (ED), and urinary incontinence. Optimal management of PUI is unclear, however, the current gold standard is placement of a suprapubic cystostomy with delayed urethroplasty (SCDU) performed several months later. Another option is early primary realignment (PR) with urethral catheter, performed either open or endoscopically. Through a systematic review and meta-analysis, we aimed to compare PR and SCDU regarding stricture, ED, and urinary incontinence rates. In light of advancing endoscopic techniques, we also aimed to compare early endoscopic realignment (EER) alone with SCDU. Methods: PubMed, Medline, and Embase were searched for eligible studies comparing PR, including EER, and suprapubic cystostomy plus delayed urethroplasty from database inception until July 17th, 2018. We also reviewed reference lists from relevant articles. Study quality assessment was conducted using a modified New-
\end{abstract}

\section{KARGER}

Fax +41613061234

E-Mail karger@karger.com

www.karger.com
(C) 2019 The Author(s)

Published by S. Karger AG, Basel Open access

This article is licensed under the Creative Commons AttributionNonCommercial-NoDerivatives 4.0 International License (CC BYNC-ND) (http://www.karger.com/Services/OpenAccessLicense). NC-ND) (http://www.karger.com/Services/OpenAccessLicense).
Usage and distribution for commercial purposes as well as any disUsage and distribution for commercial purposes as well as
tribution of modified material requires written permission.
castle-Ottawa (mNOS) scale (maximum score 9). Results: From 461 identified articles, 13 studies encompassing 414 PR and 308 SCDU patients met our eligibility criteria. Twelve studies were retrospective non-randomized case studies, with 1 prospective randomized case study. Included studies were of moderately low quality (mNOS mean score: 6.0 \pm 0.6 ). Meta-analysis demonstrated that PR and SCDU had similar stricture rates [odds ratio (OR): $2.14 ; 95 \%$ confidence interval $(\mathrm{Cl})$ : $0.67-6.85 ; \mathrm{p}=0.20$ ], similar rates of ED (OR: 1.06; $95 \% \mathrm{Cl}: 0.62-1.81 ; \mathrm{p}=0.84$ ), and similar rates of urinary incontinence (OR: $0.94 ; 95 \% \mathrm{Cl}: 0.49-1.79 ; \mathrm{p}=0.86)$. Six studies compared EER alone (229 patients) versus SCDU (195 patients). Meta-analysis demonstrated that these modalities also had similar stricture rates (OR: $4.14 ; 95 \%$ Cl: 0.76-22.45; $\mathrm{p}=0.10)$, similar rates of ED (OR: $0.79 ; 95 \% \mathrm{Cl}: 0.41-1.54 ; \mathrm{p}$ $=0.49$ ), and similar rates of urinary incontinence (OR: 1.10; $95 \% \mathrm{Cl}: 0.48-2.53 ; p=0.82)$. Conclusion: For PUI patients, neither PR nor EER produces superior outcomes compared to SCDU regarding stricture, $E D$, and urinary incontinence rates. The quality of studies in the literature, however, is very poor, with the majority of studies being non-randomized retrospective case studies with potentially high bias. Additional high-quality research, particularly prospective studies and randomized controlled trials, are needed to strengthen the evidence base.

(c) 2019 The Author(s) Published by S. Karger AG, Base 


\section{Introduction}

Pelvic fracture associated with major trauma can be complicated by posterior urethral injury (PUI), with studies estimating incidence of this between 1.5 and $25 \%$ [1-3]. In these cases, the prostate gland is forced into the perineal membrane, with the urethra subsequently stretched and injured.

PUI can produce considerable morbidity, including urethral stricture, erectile dysfunction (ED), and urinary incontinence. The aim of immediate management of PUI, after patient stabilisation, is to divert urine in order to prevent extravasation and reduce inflammation of the traumatised region. The most favorable immediate management technique, however, is unclear in regard to reducing morbidity and optimising long-term outcome, and has changed repeatedly over time.

The two most common modern techniques used to treat PUI are primary realignment (PR) and suprapubic cystostomy with delayed urethroplasty (SCDU). These techniques have replaced immediate open suture repair, either by a perineal or retropubic approach, owing to better safety and long-term outcomes [4-8]. PR is performed early in a patient's management and aims to bring the 2 ends of the urethra together in parallel over a urethral catheter in order to facilitate healing. Whilst this technique avoids retropubic dissection, concerns regarding rates of ED and urinary incontinence led to the use of suprapubic cystostomy becoming more popular [8]. PR is then followed by elective, delayed urethroplasty usually at least 3 months post-injury. In patients treated by this technique, development of a urethral stricture is inevitable. However, the use of the suprapubic cystostomy ensures that this stricture is due to the original injury and not due to trauma from the realignment process, and is thus more amenable to urethroplasty once inflammation in the region subsides $[9,10]$. SCDU is still a popular approach, however, advancements in endoscopy in the 1990s has led to primary early endoscopic realignment (EER) emerging as a rivalling, minimally-invasive treatment option [11-13]. Performed with the same rationale as open PR, EER usually involves retrograde flexible cystoscopy with simultaneous antegrade cystoscopy performed via a cystostomy with the aim of correctly placing a urethral catheter $[14,15]$.

The aim of this systematic review with meta-analysis was to critically analyze the current difference as of July 2018 between PR and SCDU in the treatment of PUI patients. In light of advancing endoscopic techniques, we also aimed to compare EER with SCDU. In order to evaluate these techniques, we aimed to review and compare rates of stricture formation, ED, and urinary incontinence.

\section{Materials and Methods}

\section{Search Strategy}

This search was performed according to the Preferred Items for Systematic Reviews and Meta-analysis (PRISMA) criteria. A systematic literature search was performed on July 17th, 2018. PubMed, Medline, and Embase databases were searched for studies published from database inception until the search date. A comprehensive search string using the following terms was used: 'realignment', 'alignment', 'cystostomy', 'urethroplasty', 'anastomosis', 'disruption', 'injury', 'trauma', 'distraction', 'tear', 'rupture', and 'urethra'. Search string used for PubMed, Medline, and Embase was [('realignment' OR 'alignment') AND ('cystostomy' OR 'urethroplasty') OR 'anastomosis'] AND ('disruption' OR 'injury' OR 'trauma' OR 'distraction' OR 'tear' OR 'rupture') AND ('urethra' OR 'urethral'). We also reviewed reference lists from related articles to identify further potential eligible studies.

\section{Eligibility Criteria}

The titles and abstracts of all articles returned by our search were assessed for potential relevance. If deemed relevant, the fulltext of that article was evaluated against our eligibility criteria. We only included studies that compared PR (open, endoscopic, or both) against SCDU in pelvic fracture patients. This included studies analyzing adult patients, pediatric patients, or both. Due to the paucity of relevant studies, we did not place limitations on study design and also chose to include scientific meeting abstracts if eligible.

Articles focusing on anterior urethral injuries, animal studies, or diagnostics were excluded. Review articles, non-comparative studies, letters to editors, and commentaries were also excluded unless they included relevant, eligible primary data.

\section{Data Extraction}

Data were extracted from each eligible study and entered into a pre-designed single spreadsheet. Data headings included study design, modalities compared, recruitment period, location, follow-up duration, number of patients, age of patients, and comparative data regarding our three primary outcomes. These outcomes were post-intervention stricture rate, ED rate, and urinary incontinence rate.

\section{Risk-of-Bias Assessment}

We anticipated that the majority of, if not all, studies deemed eligible would be comparative case studies, rather than randomized controlled trials. Therefore, we used the modified Newcastle-Ottawa scale (mNOS) for case-control studies (maximum score 9) to evaluate the methodological quality of eligible studies [16]. This scale has been chosen in other reviews where case studies were the only study design found [17-19]. We defined high quality as a score of 7, and low quality as a score of 6. Publication bias was evaluated by inspection of funnel plots. 


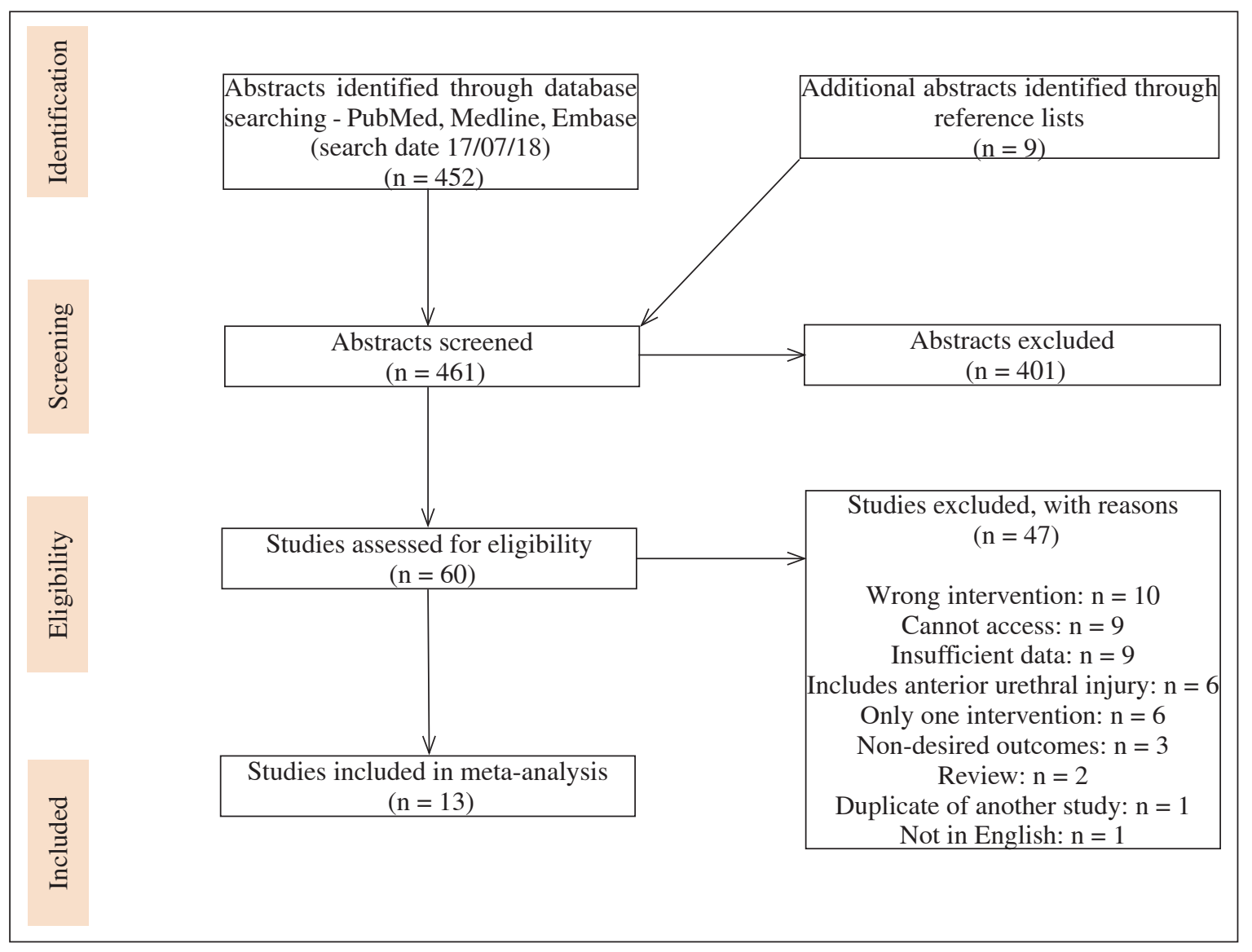

Fig. 1. Search process employed.

Table 1. Characteristics of included studies

\begin{tabular}{|c|c|c|c|c|c|c|c|c|}
\hline Study & $\begin{array}{l}\text { Study } \\
\text { design }\end{array}$ & $\begin{array}{l}\text { Treatment } \\
\text { modalities }\end{array}$ & $\begin{array}{l}\text { Recruitment } \\
\text { period }\end{array}$ & Location & $\begin{array}{l}\text { No. patients } \\
\text { (PR/SCDU) }\end{array}$ & $\begin{array}{l}\text { No. patients } \\
\text { (EER/SCDU) }\end{array}$ & $\begin{array}{l}\text { Mean age, years } \\
\text { (PR/EPR/SCDU) }\end{array}$ & $\begin{array}{l}\text { Mean follow-up } \\
\text { duration, months } \\
\text { (PR/EER/SCDU) }\end{array}$ \\
\hline Avanoglu et al. [20], 1996 & RNCS & PR vs. SCDU & $1980-1993$ & Turkey & $14 / 4$ & - & $10.4 \pm 3.4 / 6.0 \pm 1.4$ & $6-12$ \\
\hline Kamal [21], 2000 & RNCS & PR vs. SCDU & $1985-1998$ & Saudi Arabia & $9 / 3$ & - & $35.3(20-47)$ & $34(14-36)$ \\
\hline Moudouni et al. [22], 2001 & RNCS & EER vs. SCDU & 1989-1998 & Morocco & $30 / 10$ & $30 / 10$ & N/A & $30(12-72)$ \\
\hline Ku et al. [23], 2002 & RNCS & PR vs. SCDU & N/A & Korea & $35 / 20$ & - & N/A & N/A \\
\hline Balkan et al. [24], 2005 & RNCS & PR vs. SCDU & 1990-2003 & Turkey & $12 / 8$ & - & $7.41 \pm 1.25 / 7.06 \pm 2.04$ & $4.92 \pm 2.36 / 5.13 \pm 2.85$ \\
\hline Onen et al. [25], 2005 & RNCS & PR vs. SCDU & $1986-2000$ & Turkey & $22 / 16$ & - & 'pediatric' & $144(48-204)$ \\
\hline Nerli et al. [26], 2008 & RNCS & EER/PR vs. SCDU & $1990-2005$ & India & $12 / 10$ & $7 / 10$ & $11.3(5-15)$ & $25-112 / 27-132$ \\
\hline Boulma et al. [27], 2013 & RNCS & EER vs. SCDU & $2002-2009$ & Tunisia & $20 / 10$ & $20 / 10$ & $37(17-73)$ & $21(6-60)$ \\
\hline Gomez et al. [28], 2013 & RNCS & PR vs. SCDU & $1986-2012$ & Chile & $18 / 43$ & - & $34(15-69)$ & N/A \\
\hline Abdalla et al. [29], 2015 & PRCS & EER vs. SCDU & 2009-2013 & Egypt & $16 / 16$ & $16 / 16$ & $30(16-36) / 27.5(16-38)$ & $12-30$ \\
\hline Johnsen et al. [30], 2015 & RNCS & EER vs. SCDU & $2000-2014$ & USA & $27 / 11$ & $27 / 11$ & $34 \pm 14 / 42 \pm 14$ & $40(1-152)$ \\
\hline Furrer et al. [31], 2017 & RNCS & EER/PR vs. SCDU & N/A & Switzerland & $70 / 19$ & N/A & N/A & N/A \\
\hline Zou et al. [32], 2017 & RNCS & EER vs. SCDU & 2004-2014 & Chile & $129 / 138$ & $129 / 138$ & $48(8-78) / 46.7(8-74)$ & $45(17-65) / 39(19-58)$ \\
\hline
\end{tabular}

RNCS = Retrospective non-randomized case study; PRCS = prospective randomized case study. 
Table 2. Quality assessment of included studies using a modified Newcastle-Ottawa scale (maximum score 9) [18]

\begin{tabular}{lllll}
\hline Study & $\begin{array}{l}\text { Selection } \\
(/ 4)\end{array}$ & $\begin{array}{l}\text { Comparability } \\
(/ 2)\end{array}$ & $\begin{array}{l}\text { Exposure } \\
(/ 3)\end{array}$ & $\begin{array}{l}\text { Total } \\
(/ 9)\end{array}$ \\
\hline Avanoglu et al. [20], 1996 & 3 & 0 & 2 & 5 \\
Kamal [21], 2000 & 3 & 0 & 3 & 6 \\
Moudouni et al. [22], 2001 & 3 & 0 & 3 & 6 \\
Ku et al. [23], 2002 & 1 & 0 & 2 & 3 \\
Balkan et al. [24], 2005 & 3 & 1 & 3 & 7 \\
Onen et al. [25], 2005 & 3 & 0 & 3 & 6 \\
Nerli et al. [26], 2008 & 2 & 0 & 3 & 5 \\
Boulma et al. [27], 2013 & 3 & 0 & 3 & 6 \\
Gomez et al. [28], 2013 & 4 & 1 & 3 & 8 \\
Abdalla et al. [29], 2015 & 3 & 1 & 3 & 7 \\
Johnsen et al. [30], 2015 & 3 & 1 & 2 & 6 \\
Furrer et al. [31], 2017 & 4 & 1 & 3 & 8 \\
Zou et al. [32], 2017 & 2 & 1 & 3 & 6 \\
\hline
\end{tabular}

\section{Subgroup Analysis}

We hypothesized a priori that, due to advancements in endoscopic techniques and their minimally invasive nature, EER may produce better outcomes compared to open PR. Therefore, we chose to analyze EER alone versus SCDU as a subgroup.

\section{Statistical Analysis}

For our three outcome measures, rates of each were determined and hence odds ratios (OR) with $95 \%$ confidence interval (CI) were calculated. A p value of $<0.05$ was used to indicate a significant difference of treatment effect. The chi-squared test was used to assess for statistical heterogeneity, with $\mathrm{p}<0.1$ indicating heterogeneity. In the presence of heterogeneity, we used a random-effects model for meta-analysis. If data proved to be homogenous, a fixed-effects model was used. All statistical analysis was performed with Review Manager (v.5.3, 2014; Cochrane Initiative).

\section{Results}

\section{Study Characteristics}

Our search returned 461 articles in total, with 13 studies meeting our eligibility criteria for inclusion (fig. 1) [20-32]. These 13 studies encompassed 414 PR and 308 SCDU patients. Six of these studies compared EER alone $(\mathrm{n}=229)$ against $\operatorname{SCDU}(\mathrm{n}=195)[22,26,27,29,30$, 32]. One study included both open PR and EER patients but did not provide separate data for each modality [31].

Table 1 displays the characteristics of included studies. Ten studies were full-text studies [20-27, 30, 32], and 3 were scientific meeting abstracts [28, 29,31]. Twelve studies were retrospective non-randomized case studies [20$28,30-32]$, with one prospective non-randomized case study [29]. There were no randomized controlled trials identified. No studies reported matching patient groups.
These 13 comparative case studies were overall of moderately low quality [mean mNOS score 6.0, standard deviation (SD) 0.6] (table 2). Four studies were deemed to be high-quality [24, 28, 29,31], whilst 9 were deemed to be low-quality [20-23, 25-27, 30, 32].

\section{Outcomes}

Table 3 presents outcome definitions and data.

\section{Stricture Rate}

All 13 studies were included in the meta-analysis for stricture rate for PR versus SCDU (fig. 2) [20-32]. Three studies individually indicated that SCDU produced significantly lower stricture rates [28, 29, 32]. Ten studies reported similar stricture rates [20-27, 30, 31]. No study reported a lower stricture rate following PR. Meta-analysis demonstrated that PR and SCDU had similar stricture rates (random-effects model; OR: 2.14; 95\% CI: $0.67-$ $6.85 ; \mathrm{p}=0.20)$. The data analyzed here were deemed to be heterogeneous $\left(\mathrm{p}<0.00001, \mathrm{I}^{2}=87 \%\right)$.

Six studies were included in the subgroup meta-analysis for stricture rate for EER versus SCDU (fig. 3). Of these, 2 studies indicated significantly lower stricture rates following SCDU [29, 32]. Four studies reported similar stricture rates [22, 26, 27, 30], and no study reported lower stricture rates following EER. Meta-analysis indicated that EER and SCDU carry similar stricture rates (random effects model; OR: 4.14; 95\% CI: 0.76$22.45 ; \mathrm{p}=0.10)$. The data analyzed here were deemed to be heterogeneous $\left(\mathrm{p}<0.00001, \mathrm{I}^{2}=87 \%\right)$, hence inclusion of EER could not explain the heterogeneity observed in the overall effect for stricture rate.

\section{Erectile Dysfunction Rate}

Eight studies reported data on ED rates following PR versus SCDU and hence were included in this meta-analysis (fig. 4) [20-23, 25, 27, 29, 32]. All 8 studies reported similar rates of ED between treatment modalities. Meta-analysis indicated that PR and SCDU produce similar rates of ED (fixed effects model; OR: 1.06; 95\% CI: $0.62-1.81 ; p=0.84)$. The data analyzed here were not heterogeneous $\left(\mathrm{p}=0.52, \mathrm{I}^{2}=0 \%\right)$.

Four studies were included in the subgroup meta-analysis for EER versus SCDU (fig. 5) [22, 27, 29, 32]. All 4 studies reported similar rates of ED between treatment modalities. Meta-analysis confirmed that the EER and SCDU produce similar rates of ED (fixed effects model; OR: $0.79 ; 95 \%$ CI: $0.41-1.54 ; p=0.49)$. The data analyzed here were not heterogeneous $\left(\mathrm{p}=0.29, \mathrm{I}^{2}=20 \%\right)$. 


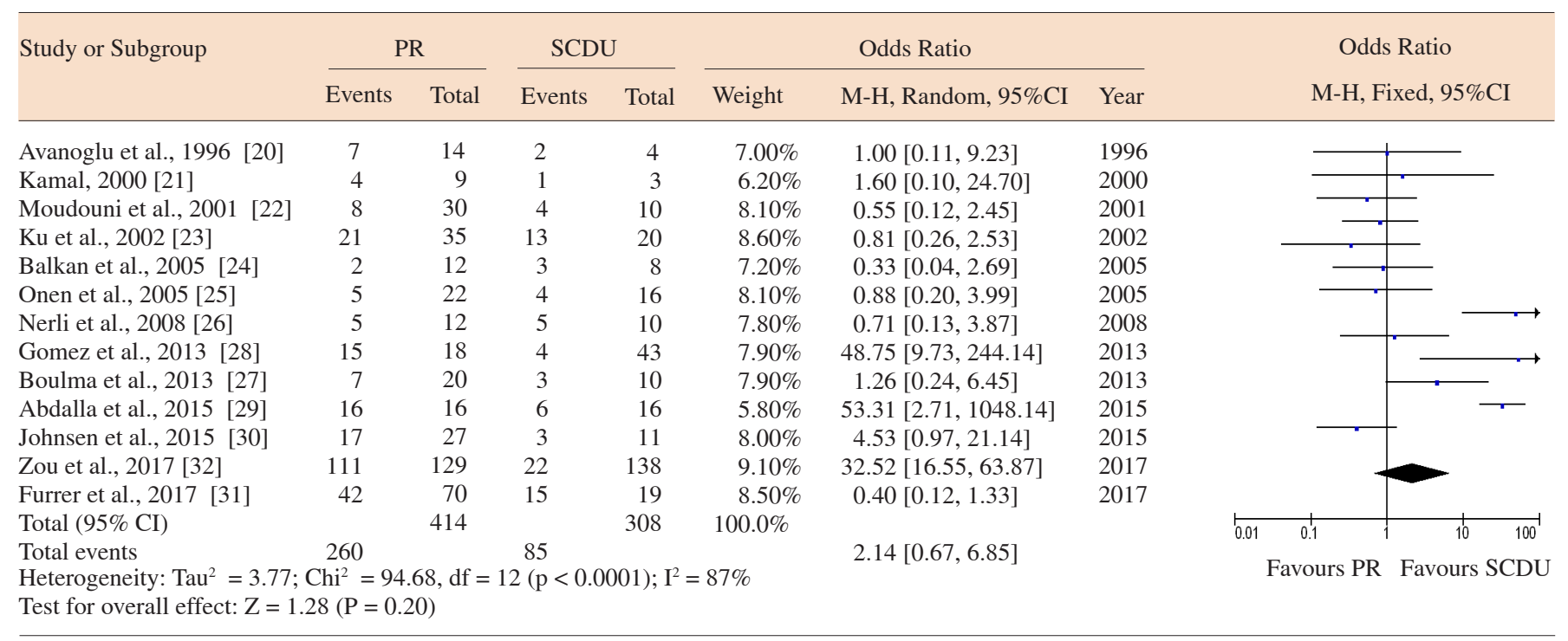

Fig. 2. Meta-analysis of stricture rate for PR versus SCDU, using a random-effects model.

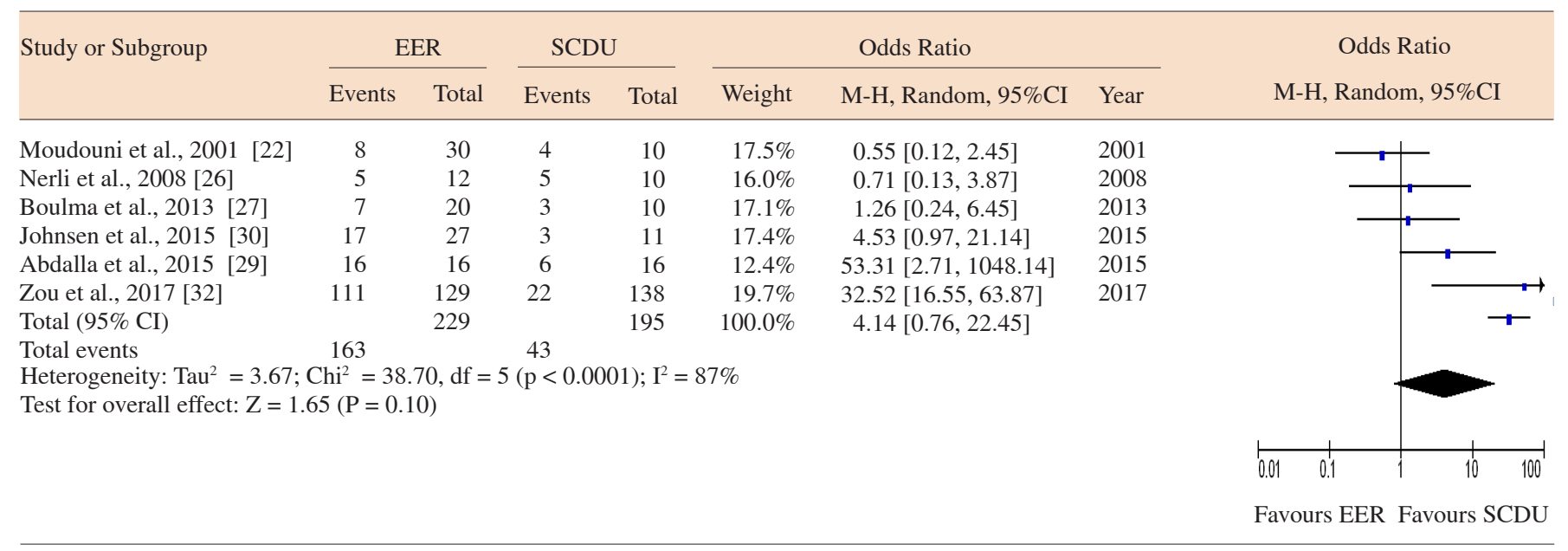

Fig. 3. Meta-analysis of stricture rate for EER versus SCDU, using a random-effects model.

\section{Urinary Incontinence Rate}

Nine studies reported data on urinary incontinence rates following PR versus SCDU and were therefore included in this meta-analysis (fig. 6) [20, 22-26, 27, $29,32]$. Two studies reported no cases of urinary incontinence following either treatment in any patient, and hence differences in treatment effects for these studies was not estimable [26, 27]. The other seven studies all indicated similar rates of urinary incontinence between treatment arms [20, 22-25, 29, 32]. Meta-analysis demonstrated that PR and SCDU produce similar rates of urinary incontinence (fixed effects model; OR: 0.94; 95\% CI: $0.49-1.79 ; \mathrm{p}=0.86)$. The data analyzed here were not heterogeneous $\left(\mathrm{p}=0.50, \mathrm{I}^{2}=0 \%\right)$. 


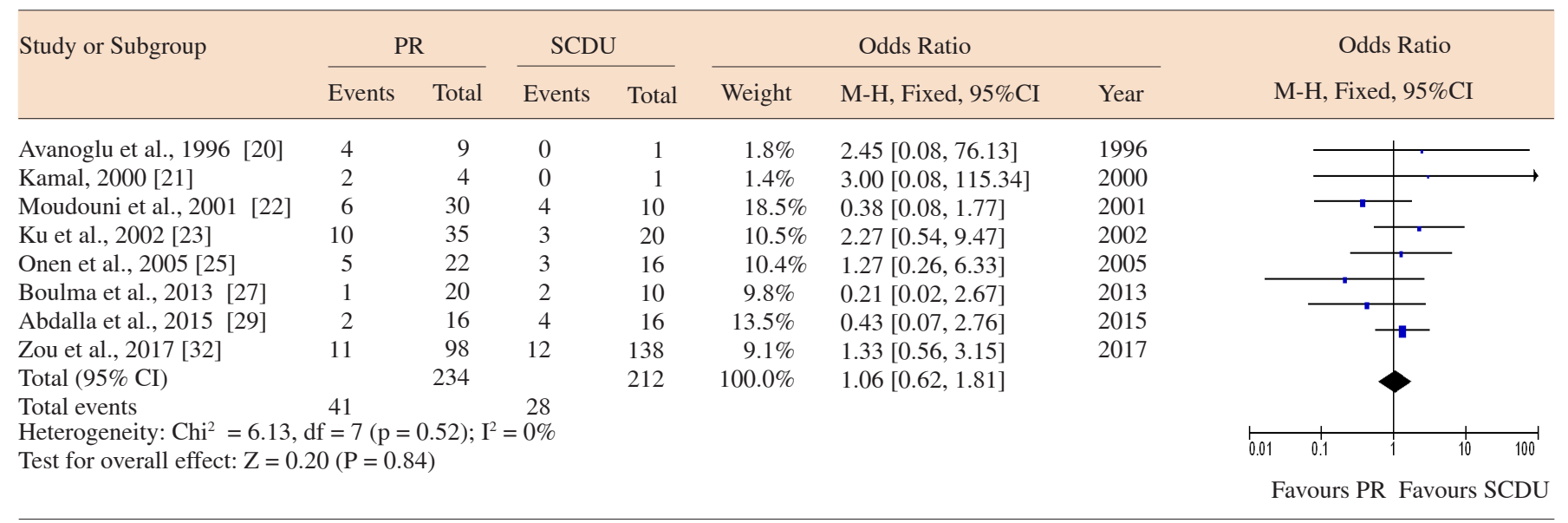

Fig. 4. Meta-analysis of ED rate for PR versus SCDU, using a fixed-effects model.

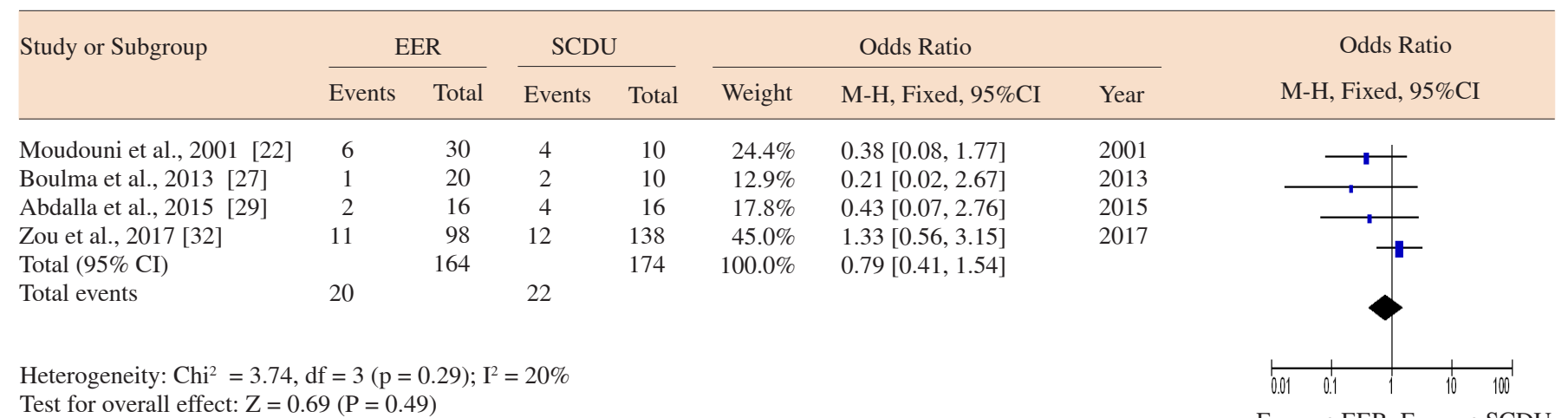

Test for overall effect: $\mathrm{Z}=0.69(\mathrm{P}=0.49)$

Favours EER Favours SCDU

Fig. 5. Meta-analysis of ED rate for EER versus SCDU, using a fixed-effects model.

\begin{tabular}{|c|c|c|c|c|c|c|c|c|}
\hline Study or Subgroup & Events & Total & Events & Total & Weight & M-H, Fixed, 95\%CI & Year & $\begin{array}{c}\text { Odds Ratio } \\
\text { M-H, Fixed, 95\% CI }\end{array}$ \\
\hline Moudouni et al., 2001 [22] & 0 & 30 & 1 & 10 & $11.4 \%$ & $0.10[0.00,2.77]$ & 2001 & \\
\hline Ku et al., 2002 [23] & 3 & 35 & 2 & 20 & $12.2 \%$ & $0.84[0.13,5.53]$ & 2002 & \\
\hline Balkan et al., 2005 [24] & 1 & 12 & 1 & 8 & $5.8 \%$ & $0.64[0.03,11.91]$ & 2005 & - \\
\hline Onen et al., 2005 [25] & 4 & 22 & 3 & 16 & $14.9 \%$ & $0.96[0.18,5.06]$ & 2005 & \\
\hline Abdalla et al., 2015 [29] & 0 & 16 & 2 & 16 & $12.7 \%$ & $0.18[0.01,3.97]$ & 2015 & \\
\hline Zou et al., 2017 [32] & 10 & 98 & 8 & 138 & $31.3 \%$ & $1.85[0.70,4.86]$ & 2017 & \\
\hline Total $(95 \% \mathrm{CI})$ & & 259 & & 232 & $100.0 \%$ & $0.94[0.49,1.79]$ & & \\
\hline Total events & 22 & & 19 & & & & & 0.01 \\
\hline \multicolumn{8}{|c|}{$\begin{array}{l}\text { Heterogeneity: } \mathrm{Chi}^{2}=5.33, \mathrm{df}=6(\mathrm{p}=0.50) ; \mathrm{I}^{2}=0 \% \\
\text { Test for overall effect: } \mathrm{Z}=0.18(\mathrm{P}=0.86)\end{array}$} & Favours PR Favours SCDU \\
\hline
\end{tabular}

Fig. 6. Meta-analysis of urinary incontinence rate for PR versus SCDU, using a fixed-effects model. 
Five studies were included in the subgroup meta-analysis for EER versus SCDU (fig. 7) [22, 26, 27, 29, 32]. Two studies reported no cases of urinary incontinence in either treatment arm [26, 27]. The other 3 studies all indicated similar rates of urinary incontinence $[22,29,32]$. Meta-analysis showed that EER and SCDU produce similar rates of urinary incontinence (fixed effects model; OR: $1.10 ; 95 \%$ CI: $0.48-2.53 ; \mathrm{p}=0.82)$. The data analyzed here were not heterogeneous $(\mathrm{p}=0.11, \mathrm{I} 2=55 \%)$.

\section{Publication Bias}

Funnel plots constructed for stricture rate following PR versus SCDU (13 studies) (fig. 8), and for EER versus SCDU (6 studies) did not demonstrate symmetry, suggesting a degree of publication bias for these outcomes. Funnel plots constructed for ED or urinary incontinence rates, for PR or EER versus SCDU, all demonstrated symmetry, suggesting a lack of publication bias.

\section{Summary of Findings}

The GRADE system was used to evaluate the quality of evidence [33]. This quality was deemed as very low for all outcomes with all comparisons (table 4).

\section{Discussion}

\section{Previous Systematic Reviews}

Three systematic reviews have previously compared PR with SCDU [34-36], with one of these exclusively comparing EER against SCDU [36]. Of the 2 reviews that performed meta-analysis, both concluded that PR produces a significantly reduced stricture rate compared to SCDU $[34,35]$. These also indicated similar ED and urinary incontinence rates between PR and SCDU. The present review is the first to perform meta-analysis comparing EER alone against SCDU.

\section{Stricture Rate}

The meta-analysis performed to assess stricture rate indicated similar rates between PR and SCDU $(p=0.20)$, and between EER alone and SCDU $(\mathrm{p}=0.10)$. That PR and SCDU produce similar stricture rates is surprising given previous meta-analysis indicating an advantage for PR [34, 35].

Despite the minimally invasive nature of EER, this technique also led to similar stricture rates compared to SCDU. There is a paucity of EER studies in the literature, so inclusion of future studies may lead a significant difference in treatment effects during meta-analysis. Fur-

Pelvic Fracture-Associated Posterior Urethral Injury thermore, of the 229 EER patients analyzed here, 163 $(71.2 \%)$ developed strictures, which was a poor figure. For now, therefore, we question whether centers that perform SCDU as standard for PUI patients would indeed benefit from switching to EER as first-line management.

It is also arguable that the nature of EER is less desirable for patients. EER, whilst it can produce durable patency, can also necessitate repeated, painful dilatations, with the threat of acute urinary retention in-between. One study of 17 PUI patients treated by EER reported a median of 4 endoscopic urethral procedures per patient at mean follow-up of 41 months [37]. This included a patient who underwent 36 such procedures. The notion that EER requires more additional procedures is also confirmed by several studies included in the present review [29, 32]. Repeated procedures can lead to further urethral injury and actually worsen scarring, with subsequent pain, bleeding, and formation of fistulas. There is also evidence that strictures develop up to 16 months later following EER compared to placement of a suprapubic cystostomy [32]. Therefore, whilst the rationale behind EER is plausible, it can lead to chronic stricture and a longer clinical course, and therefore may not be preferential for many patients, particularly younger ones.

In contrast to PR or EER, the placement of a suprapubic cystostomy in the emergency setting means that urinary diversion can be achieved quickly and other life-threatening injuries, particularly in the context of pelvic fracture, can be managed. This means that a resultant stricture is almost inevitable, but elective delayed urethroplasty once the patient has recovered from other injuries can be very effective. An important animal study demonstrated that, compared to catheter realignment, urethral healing is enhanced when the ends of the urethra are precisely opposed, as is the case with the tension-free anastomosis performed in urethroplasty [38].

Our conclusions are weakened by the poor quality of included studies. Retrospective observational studies, of which all except one study were, are very prone to bias. Indeed, stricture rate data for PR versus SCDU and EER versus SCDU was deemed to be statistically heterogeneous. This may be explained by inclusion of multiple different realignment techniques. Indeed, the patients analyzed here were treated between 1980 and 2014, over which period techniques and equipment have altered. Open PR, for example, can be performed by insertion of a Foley catheter, interlocking sounds and railroading methods.

Another cause of heterogeneity may be differences in the time to PR or EER, and the time to delayed urethroplasty. Only one study mentioned the time to PR

Curr Urol 2019;13:113-124 


\begin{tabular}{|c|c|c|c|c|c|c|c|c|}
\hline \multirow[t]{2}{*}{ Study or Subgroup } & \multicolumn{2}{|c|}{ EER } & \multicolumn{2}{|c|}{ SCDU } & \multicolumn{3}{|c|}{ Odds Ratio } & \multirow{2}{*}{$\begin{array}{c}\text { Odds Ratio } \\
\text { M-H, Fixed, 95\%CI }\end{array}$} \\
\hline & Events & Total & Events & Total & Weight & M-H, Fixed, 95\%CI & Year & \\
\hline Nerli et al., 2008 [26] & 0 & 7 & 0 & 10 & & Not estimable & 2008 & \\
\hline Boulma et al., 2013 [27] & 0 & 20 & 0 & 10 & & Not estimable & 2013 & \\
\hline Abdalla et al., 2015 [29] & 0 & 16 & 2 & 16 & $23.0 \%$ & $0.18[0.01,3.97]$ & 2015 & \\
\hline Zou et al., 2017 [32] & 10 & 98 & 8 & 138 & $56.4 \%$ & $1.85[0.70,4.86]$ & 2017 & - \\
\hline \multicolumn{8}{|c|}{$\begin{array}{l}\text { Heterogeneity: } \mathrm{Chi}^{2}=4.41, \mathrm{df}=2(\mathrm{p}=0.11) ; \mathrm{I}^{2}=55 \% \\
\text { Test for overall effect: } \mathrm{Z}=0.23(\mathrm{P}=0.82)\end{array}$} & 0.01 \\
\hline
\end{tabular}

Fig. 7. Meta-analysis of urinary incontinence rate for EER versus SCDU, using a fixed-effects model.

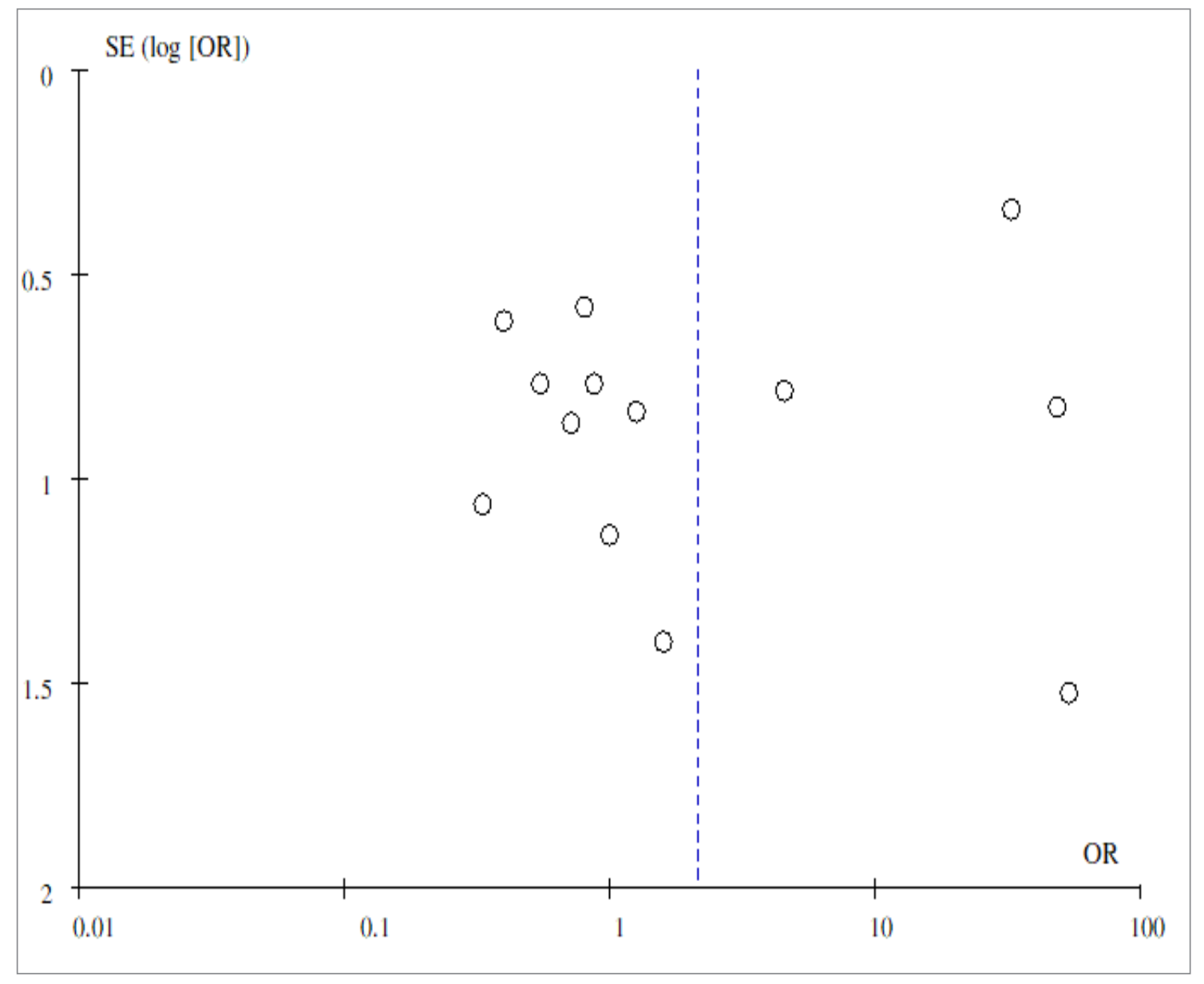

Fig. 8. Funnel plot of stricture rates for PR versus SCDU. 
[24], and another mentioning time to EER [32]. Just 5 studies mentioned the time to delayed urethroplasty [21, 24, 26, 28, 30]. Furthermore, just 5 studies mentioned how patients were allocated to receive each treatment, with no studies reporting on patient group matching. Only one study randomized patients [29], with 2 studies indicating allocation was based on surgeon preference $[20,28]$, and one study preferring SCDU only in patients with isolated or incomplete PUI [25]. Although we have used a random-effects statistical model to combat heterogeneity, significant problems with or non-reporting of study methodology means that our conclusions become very weak. We also encountered a degree of publication bias for our stricture rate analysis (fig. 8). Of course, pelvic fractures are generally caused by major trauma, so conducting high-quality randomized controlled trials in this area is inherently logistically difficult.

\section{ED Rate}

Of the 8 studies reporting on it, ED affected 41/234 (17.5\%) and 28/212 (13.2\%) of PR and SCDU patients respectively, with no significant difference between the groups $(\mathrm{p}=0.84)$. Although there was no statistical difference for rates between EER and SCDU, a considerable 163/229 (71.2\%) of EER patients developed ED.

All three previous reviews concluded that ED is more of a consequence of the initial injury rather than management [34-36]. However, distinguishing between de novo dysfunction and dysfunction due to management is difficult without serial measurements of erectile function before and after PUI, and before and after any procedures. ED is caused by damage to the neurovascular bundle, so it is plausible that open PR would increase the risk of ED through additional manipulation of traumatised tissue. It is also plausible that EER would provide excellent outcomes as the endoscope should not access the periprostatic tissue. In consideration of this rationale, we are unable to explain the comparatively high (71.2\%), albeit statistically similar, rate of ED in EER patients.

Once again, the lack of standardisation as to how patients were allocated to receive each treatment could be important. If more severely injured patients were chosen to receive one treatment this will bias the subsequent meta-analysis. Furthermore, evaluating ED was not standardised either. Five studies did not report how they defined ED [20, 21, 23, 27, 29], two used patient self-reporting $[22,32]$, and one used an unspecified patient questionnaire [25] (table 3). Standardised use of a validated questionnaire such as the International Index of Erectile Function questionaire would improve data quality [39].

Pelvic Fracture-Associated Posterior Urethral Injury

\section{Urinary Incontinence Rate}

Urinary incontinence was an uncommon morbidity, affecting 22/259 (8.5\%) of PR patients, 10/171 (5.8\%) of EER patients, and 19/232 (8.2\%) of SCDU patients. We did not detect statistical differences for this outcome between PR and SCDU $(p=0.86)$ and between EER and $\operatorname{SCDU}(\mathrm{p}=0.82)$ patients.

Two previous reviews, similar to $\mathrm{ED}$, concluded that urinary incontinence was more of a consequence of the initial injury than any procedure $[35,36]$. This is supported by the results of our meta-analysis. Our conclusions, also similar to ED, suffer from non-standardised patient allocation and definitions of urinary incontinence. Five studies did not report what definition they used [20, $23,24,27,29]$, three used patient self-reporting [22, 26, 32 ], and just one used a patient questionnaire (unspecified) with further imaging techniques [25] (table 3). Using a validated questionnaire like the International Consultation on Incontinence Modular Questionnaire would improve data for this outcome, and would also enable identification of the severity of the incontinence [40]. In any case, the $5.8-8.5 \%$ rates of urinary incontinence are low.

\section{Limitations}

The present systematic review with meta-analysis has several limitations. As mentioned, the major limitation, shared also by all previous reviews, is study quality [34-36]. The current studies being mostly retrospective, with heterogeneity, serious selection bias, non-standardised outcome reporting and a paucity of included patients means that meaningful and robust conclusions become difficult to make. We have touched on the difficulties of conducting well-designed randomized controlled trials in major trauma, but prospective randomized studies, similar to one we included, would still increase the quality of the evidence base and are an important research recommendation in this area [29].

Although we have only analyzed posterior urethral injuries, our analysis are also weakened by our inclusion of both adult and pediatric patients. We anticipated retrieving a small number of studies reporting on a small number of patients, hence we included both groups in order to expand the number of patients in this analysis.

A third limitation is a lack of grading of urethral injury severity by, for example, the Colapinto and McCallum or American Association for the Surgery of Trauma systems [41, 42]. Only 2 studies performed such grading $[23,30]$. Reporting on the severity of the initial injury would give further context to our results. For example, 
Table 3. Outcome definitions and data

\begin{tabular}{|c|c|c|c|c|c|c|c|}
\hline Study & Technique & $\begin{array}{l}\text { Stricture rate } \\
(\%)\end{array}$ & $\begin{array}{l}\text { Definition of } \\
\text { stricture }\end{array}$ & ED rate $(\%)$ & $\begin{array}{l}\text { Definition } \\
\text { of ED }\end{array}$ & $\begin{array}{l}\text { Urinary } \\
\text { incontinence } \\
\text { rate }(\%)\end{array}$ & $\begin{array}{l}\text { Definition of urinary } \\
\text { incontinence }\end{array}$ \\
\hline Avanoglu et al. [20], 1996 & $\begin{array}{l}\text { total PR } \\
\text { SCDU }\end{array}$ & $\begin{array}{l}7 / 20(35.0) \\
3 / 10(30.0)\end{array}$ & $\begin{array}{l}\text { endoscopy, uroflowm- } \\
\text { etry }\end{array}$ & $\begin{array}{l}4 / 9(44.4) \\
0 / 1(0)\end{array}$ & NR & $\begin{array}{l}4 / 14(28.6) \\
2 / 4(50.0)\end{array}$ & NR \\
\hline Kamal [21], 2000 & $\begin{array}{l}\text { total PR } \\
\text { SCDU }\end{array}$ & $\begin{array}{l}4 / 9(44.4) \\
1 / 3(33.3)\end{array}$ & $\begin{array}{l}\text { urine flow rate, retrog- } \\
\text { ade urethrography }\end{array}$ & $\begin{array}{l}2 / 4(50.0) \\
0 / 1(0)\end{array}$ & NR & $\begin{array}{l}\text { NR } \\
\text { NR }\end{array}$ & - \\
\hline Moudouni et al. [22], 2001 & $\begin{array}{l}\text { total PR } \\
\text { EER only } \\
\text { SCDU }\end{array}$ & $\begin{array}{l}8 / 30(26.7) \\
8 / 30(26.7) \\
4 / 10(40.0)\end{array}$ & urine flow rate $<15 \mathrm{ml} / \mathrm{s}$ & $\begin{array}{l}6 / 30(20.0) \\
6 / 30(20.0) \\
4 / 10(40.0)\end{array}$ & patient report & $\begin{array}{l}0 / 30(0) \\
0 / 30(0) \\
1 / 10(10.0)\end{array}$ & patient report \\
\hline Ku et al. [23], 2002 & $\begin{array}{l}\text { total PR } \\
\text { SCDU }\end{array}$ & $\begin{array}{l}21 / 35(60.0) \\
13 / 20(65.0)\end{array}$ & retrograde urethrography & $\begin{array}{l}10 / 35(28.6) \\
3 / 20(15.0)\end{array}$ & NR & $\begin{array}{l}3 / 35(8.6) \\
2 / 20(10.0)\end{array}$ & NR \\
\hline Balkan et al. [24], 2005 & $\begin{array}{l}\text { total PR } \\
\text { SCDU }\end{array}$ & $\begin{array}{l}2 / 12(16.7) \\
3 / 8(37.5)\end{array}$ & retrograde urethrography & $\begin{array}{l}\mathrm{NR} \\
\mathrm{NR}\end{array}$ & - & $\begin{array}{l}1 / 12(8.3) \\
1 / 8(12.5)\end{array}$ & NR \\
\hline Onen et al. [25], 2005 & $\begin{array}{l}\text { total PR } \\
\text { SCDU }\end{array}$ & $\begin{array}{l}5 / 22(22.7) \\
4 / 16(25.0)\end{array}$ & $\begin{array}{l}\text { ultrasound, retrograde } \\
\text { urethrography, voiding } \\
\text { cystourethrography, } \\
\text { cystourethroscopy }\end{array}$ & $\begin{array}{l}5 / 22(22.7) \\
3 / 16(18.8)\end{array}$ & $\begin{array}{l}\text { patient } \\
\text { questionnaire }\end{array}$ & $\begin{array}{l}4 / 22(18.2) \\
3 / 16(18.8)\end{array}$ & $\begin{array}{l}\text { patient questionnaire, post- } \\
\text { void residual urine volume, } \\
\text { urethrography, uroflowme- } \\
\text { try, urethral pressure profile }\end{array}$ \\
\hline Nerli et al. [26], 2008 & $\begin{array}{l}\text { total PR } \\
\text { EER only } \\
\text { SCDU }\end{array}$ & $\begin{array}{l}5 / 12(41.7) \\
4 / 7(57.1) \\
5 / 10(50.0)\end{array}$ & symptoms & $\begin{array}{l}\text { NR } \\
\text { NR } \\
\text { NR }\end{array}$ & - & $\begin{array}{l}0 / 12(0) \\
0 / 7(0) \\
0 / 10(0)\end{array}$ & patient report \\
\hline Boulma et al. [27], 2013 & $\begin{array}{l}\text { total PR } \\
\text { EER only } \\
\text { SCDU }\end{array}$ & $\begin{array}{l}7 / 20(35.0) \\
7 / 20(35.0) \\
3 / 10(30.0)\end{array}$ & retrograde urethrography & $\begin{array}{l}1 / 20(5.0) \\
1 / 20(5.0) \\
2 / 10(20.0)\end{array}$ & NR & $\begin{array}{l}0 / 20(0) \\
0 / 20(0) \\
0 / 10(0)\end{array}$ & NR \\
\hline Gomez et al. [28], 2013 & $\begin{array}{l}\text { total PR } \\
\text { SCDU }\end{array}$ & $\begin{array}{c}15 / 18(83.3) \\
4 / 43(9.3)\end{array}$ & NR & $\begin{array}{l}\mathrm{NR} \\
\mathrm{NR}\end{array}$ & - & $\begin{array}{l}\mathrm{NR} \\
\mathrm{NR}\end{array}$ & - \\
\hline Abdalla et al. [29], 2015 & $\begin{array}{l}\text { total PR } \\
\text { EER only } \\
\text { SCDU }\end{array}$ & $\begin{array}{c}16 / 16(100.0) \\
16 / 16(100.0) \\
6 / 16(37.5)\end{array}$ & urine flow rate $<15 \mathrm{ml} / \mathrm{s}$ & $\begin{array}{l}2 / 16(12.5) \\
2 / 16(12.5) \\
4 / 16(25.0)\end{array}$ & NR & $\begin{array}{l}0 / 16(0) \\
0 / 16(0) \\
2 / 16(12.5)\end{array}$ & NR \\
\hline Johnsen et al. [30], 2015 & $\begin{array}{l}\text { total PR } \\
\text { EER only } \\
\text { SCDU }\end{array}$ & $\begin{array}{r}17 / 27(63.0) \\
17 / 27(63.0) \\
3 / 11(27.3)\end{array}$ & symptoms & $\begin{array}{l}\text { NR } \\
\text { NR } \\
\text { NR }\end{array}$ & - & $\begin{array}{l}\text { NR } \\
\text { NR } \\
\text { NR }\end{array}$ & - \\
\hline Furrer et al. [31], 2017 & $\begin{array}{l}\text { total PR } \\
\text { EER only } \\
\text { SCDU }\end{array}$ & $\begin{array}{l}42 / 70(60.0) \\
\text { N/A } \\
15 / 19(78.9)\end{array}$ & NR & $\begin{array}{l}\text { NR } \\
\text { NR } \\
\text { NR }\end{array}$ & - & $\begin{array}{l}\text { NR } \\
\text { NR } \\
\text { NR }\end{array}$ & - \\
\hline Zou et al. [32], 2017 & $\begin{array}{l}\text { total PR } \\
\text { EER only } \\
\text { SCDU }\end{array}$ & $\begin{array}{r}111 / 129(86.0) \\
111 / 129(86.0) \\
22 / 138(15.9)\end{array}$ & endoscopy & $\begin{array}{l}11 / 98(11.2) \\
11 / 98(11.2) \\
12 / 138(8.7)\end{array}$ & patient report & $\begin{array}{l}10 / 98(10.2) \\
10 / 98(10.2) \\
8 / 138(5.8)\end{array}$ & patient report \\
\hline
\end{tabular}

$\mathrm{NR}=$ Not reported

Table 4. Summary of findings, including quality of evidence as assessed by GRADE [33]

\begin{tabular}{|c|c|c|c|c|c|c|c|c|}
\hline \multirow[t]{2}{*}{ Outcome } & \multirow[t]{2}{*}{ Techniques } & \multicolumn{4}{|c|}{ Quality assessment } & \multicolumn{3}{|c|}{ Summary of findings } \\
\hline & & $\begin{array}{l}\text { No. studies } \\
\text { (no. patients) }\end{array}$ & $\begin{array}{l}\text { Methodological } \\
\text { limitations }\end{array}$ & $\begin{array}{l}\text { Consistency } \\
\left(p, \mathrm{I}^{2}\right)\end{array}$ & Precision & $\begin{array}{l}\text { Relative effect } \\
\text { (odds ratio; } 95 \% \\
\text { CI, } p \text { ) }\end{array}$ & $\begin{array}{l}\text { Absolute effect } \\
\text { (risk difference; } \\
95 \% \mathrm{CI}, p \text { ) }\end{array}$ & $\begin{array}{l}\text { Quality of } \\
\text { evidence } \\
\text { (GRADE) }\end{array}$ \\
\hline \multirow[t]{2}{*}{ Stricture rate } & stricture rate & $13(722)$ & serious limitations & $<0.00001,87 \%$ & no uncertainty & $2.14(0.67-6.85,0.20)$ & $0.16(-0.09-0.41,0.20)$ & very low \\
\hline & EER vs. SCDU & $6(424)$ & serious limitations & $<0.00001,87 \%$ & no uncertainty & $4.14(0.76-22.45,0.10)$ & $0.31(0.00-0.61,0.05)$ & very low \\
\hline \multirow[t]{2}{*}{ ED rate } & ED rate & $8(446)$ & serious limitations & $0.52,0 \%$ & no uncertainty & $1.06(0.62-1.81,0.84)$ & $0.01(-0.06-0.08,0.81)$ & very low \\
\hline & EER vs. SCDU & $4(338)$ & serious limitations & $0.29,20 \%$ & no uncertainty & $0.79(0.41-1.54,0.49)$ & $-0.03(-0.10-0.05,0.49)$ & very low \\
\hline \multirow{2}{*}{$\begin{array}{l}\text { Urinary } \\
\text { incontinence rate }\end{array}$} & urinary incontinence rate & $9(491)$ & serious limitations & $0.50,0 \%$ & no uncertainty & $0.94(0.49-1.79,0.86)$ & $0.00(-0.06-0.05,0.92)$ & very low \\
\hline & EER vs. SCDU & $5(355)$ & serious limitations & $0.11,55 \%$ & no uncertainty & $1.10(0.48-2.53,0.82)$ & $0.01(-0.05-0.07,0.76)$ & very low \\
\hline
\end{tabular}

it would help determine if more severe injuries were associated with higher ED and urinary incontinence rates, and if a technique leads to better outcomes depending on injury severity.

\section{Conclusions}

For PUI patients, neither PR nor EER produces superior outcomes compared to SCDU regarding stricture, 
$\mathrm{ED}$, and urinary incontinence rates. The quality of studies in the literature, however, is very poor, with the majority of studies being non-randomized retrospective case studies with potentially high bias. Additional high-qual- ity research, particularly randomized controlled trials or prospective studies, are needed to strengthen the evidence base and subsequent conclusions.

\section{References}

1 Koraitim MM: Pelvic fracture urethral injuries: evaluation of various methods of management. J Urol 1996;156:1288-1291.

2 Basta AM, Blackmore CC, Wessells H: Predicting urethral injury from pelvic fracture patterns in male patients with blunt trauma. J Urol 2007; 177:571-575.

3 Bjurlin MA, Fantus RJ, Mellett MM, Goble SM: Genitourinary injuries in pelvic fracture morbidity and mortality using the National Trauma Data Bank. J Trauma 2009;67:10331039.

4 Young HH: Treatment of complete rupture of the posterior urethra, recent or ancient, by anastomosis. J Urol 1929;21:417-450.

5 Clark SS, Prudencio RF: Lower urinary tract injuries associated with pelvic fractures: diagnosis and management. Surg Clin North Am 1972;52:183-201.

6 Pierce JM Jr: Management of dismemberment of the prostatic-membranous urethra and ensuing stricture disease. J Urol 1972; 107:259-264.

7 Coffield KS, Weems WL: Experience with management of posterior urethral injury associated with pelvic fracture. J Urol 1977; 117:722-724.

8 Koraitim MM: Pelvic fracture urethral injuries: the unresolved controversy. J Urol 1999; 161:1433-1441.

9 Johanson B: The reconstruction in stenosis of the male urethra. Z Urol 1953;46:361-375.

10 Turner-Warwick R: Prevention of complications resulting from pelvic fracture urethral injuries--and from their surgical management. Urol Clin North Am 1989;16:335-358.

11 Cohen JK, Berg G, Carl GH, Diamond DD: Primary endoscopic realignment following posterior urethral disruption. J Urol 1991; 146:1548-1550.

12 Guille F, Cipolla B, LEVEQUE JM, Guirassy S, Olivo JF, Lobel B: Early endoscopic realignment of complete traumatic rupture of the posterior urethra. Br J Urol 1991;68:178-180.

13 Gheiler EL, Frontera JR: Immediate primary realignment of prostatomembranous urethral disruptions using endourologic techniques. Urology 1997;49:596-599.

14 Kielb SJ, Voeltz ZL, Wolf JS: Evaluation and management of traumatic posterior urethral disruption with flexible cystourethroscopy. J Trauma 2001;50:36-40.
15 Mouraviev VB, Coburn M, Santucci RA: The treatment of posterior urethral disruption associated with pelvic fractures: comparative experience of early realignment versus delayed urethroplasty. J Urol 2005;173:873876.

16 Wells GA, Shea B, O'Connell D, Peterson J, Welch V, Losos M, Tugwell P: The Newcastle-Ottawa Scale (NOS) for assessing the quality of nonrandomised studies in meta-analysis. Ottawa, Ottawa Hospital Research Institute, 2009, Available from http:// www.ohri.ca/programs/clinical_epidemiology/oxford.htm, August 18, 2018.

17 Braga LH, Pace K, DeMaria J, Lorenzo AJ: Systematic review and meta-analysis of robotic-assisted versus conventional laparoscopic pyeloplasty for patients with ureteropelvic junction obstruction: effect on operative time, length of hospital stay, postoperative complications, and success rate. Eur Urol 2009;56:848-858.

18 Wang F, Xu Y, Zhong H: Robot-assisted versus laparoscopic pyeloplasty for patients with ureteropelvic junction obstruction: an updated systematic review and meta-analysis. Scand J Urol 2013;47:251-264.

19 Light A, Karthikeyan S, Maruthan S, Elhage O, Danuser H, Dasgupta P: Peri-operative outcomes and complications after laparoscopic vs robot-assisted dismembered pyeloplasty: a systematic review and meta-analysis. BJU Int 2018;122:181-194.

20 Avanoglu A, Ulman I, Herek Ö, Özok G, Gökdemir A: Posterior urethral injuries in children. Br J Urol 1996;77:597-600.

21 Kamal BA: Primary urethral realignment in traumatic urethral rupture. Bahrain Med Bull 2000;22:64-67.

22 Moudouni S, Tazi K, Koutani A, Hachimi M, Lakrissa A: Comparative results of the treatment of post-traumatic ruptures of the membranous urethra with endoscopic realignment and surgery. Prog Urol 2001;11:56-61.

$23 \mathrm{Ku}$ JH, Jeon YS, Kim ME, Lee NK, Park YH: Comparison of long-term results according to the primary mode of management and type of injury for posterior urethral injuries. Urol Int 2002;69:227-232.

24 Balkan E, Kilic N, Dogruyol H: The effectiveness of early primary realignment in children with posterior urethral injury. Int J Urol 2005;12:62-66.
25 Onen A, Oztürk H, Kaya M, Otçu S: Longterm outcome of posterior urethral rupture in boys: a comparison of different surgical modalities. Urology 2005;65:1202-1207.

26 Nerli RB, Koura AC, Ravish IR, Amarkhed SS, Prabha V, Alur SB: Posterior urethral injury in male children: long-term follow up. J Pediatr Urol 2008;4:154-159.

27 Boulma R, Kallel Y, Sellami A, Gargouri MM, Rhouma SB, Chlif M, Fitouri Z, Horchani A, Nouira Y: Endoscopic realignment versus delayed urethroplasty in the management of post traumatic urethral disruption: report of 30 cases. Tunis Med 2013;91:332336.

28 Gomez R, Storme O, Velarde L, Finsterbusch $\mathrm{C}$ : 10 catheter realignment versus suprapubic cystostomy + delayed urethroplasty for pelvic fracture urethral injuries: A goal-oriented retrospective comparison. J Urol 2013; 189(suppl):e4.

29 Abdalla MA, Ibrahim TM, Abdel Latif AA: 340 Initial management of pelvic fracture urethral distraction injury: Urethral realignment versus suprapubic tube. Eur Urol Suppl 2015; $14:$ e340.

30 Johnsen NV, Dmochowski RR, Mock S, Reynolds WS, Milam DF, Kaufman MR: Primary endoscopic realignment of urethral disruption injuries-a double-edged sword? J Urol 2015;194:1022-1026.

31 Furrer MA, Paerli M, Thalmann G, Roth B Long-term outcome after urethral rupture: A comparison of different treatment modalities. Eur Urol Suppl 2017;16:e1190-1191.

32 Zou Q, Zhou S, Zhang K, Yang R, Fu Q: The immediate management of pelvic fracture urethral injury - endoscopic realignment or cystostomy? J Urol 2017;198:869-874.

33 Schunemann HJ, Jaeschke R, Cook DJ, Bria WF, El-Solh AA, Ernst A, Fahy BF, Gould MK, Horan KL, Krishnan JA, Manthous CA, Maurer JR, McNicholas WT, Oxman AD, Rubenfeld G, Turino GM, Guyatt G: An official ATS statement: grading the quality of evidence and strength of recommendations in ATS guidelines and recommendations. Am J Respir Crit Care Med 2006;174:605-614.

34 Barrett K, Braga LH, Farrokhyar F, Davies TO: Primary realignment vs suprapubic cystostomy for the management of pelvic fracture-associated urethral injuries: a systematic review and meta-analysis. Urology 2014;83: 924-929. 
35 Firmanto R, Irdam GA, Wahyudi I: Early realignment versus delayed urethroplasty in management of pelvic fracture urethral injury: a meta-analysis. Acta Med Indones 2016;48:99-105.

36 Elshout PJ, Veskimae E, MacLennan S, Yuan Y, Lumen N, Gonsalves M, Kitrey ND, Sharma DM, Summerton DJ, Kuehhas FE: Outcomes of early endoscopic realignment versus suprapubic cystostomy and delayed urethroplasty for pelvic fracture-related posterior urethral injuries: a systematic review. Eur Urol Focus 2017;3:545-553.
37 Tausch TJ, Morey AF: The case against primary endoscopic realignment of pelvic fracture urethral injuries. Arab J Urol 2015; 13: 13-16.

38 McRoberts JW, Ragde H: The severed canine posterior urethra: a study of two distinct methods of repair. J Urol 1970;104:724-729.

39 Rosen RC, Cappelleri JC, Smith MD, Lipsky J, Pena BM: Development and evaluation of an abridged, 5-item version of the International Index of Erectile Function (IIEF-5) as a diagnostic tool for erectile dysfunction. Int J Impot Res 1999;11:319-326.
40 Abrams P, Avery K, Gardener N, Donovan $\mathrm{J}$ : The international consultation on incontinence modular questionnaire: www.iciq.net. J Urol 2006;175:1063-1066.

41 Colapinto V, McCallum RW: Injury to the male posterior urethra in fractured pelvis: a new classification. J Urol 1977;118:575-580.

42 Moore EE, Cogbill TH, Malangoni MA, Jurkovich GJ, Shackford SR, Champion HR, McAninch JW: Organ injury scaling. Surg Clin North Am 1995;75:293-303. 